\title{
Differentiation of malignant from non- malignant portal vein thrombosis in liver cirrhosis: the challenging dilemma
}

\author{
Amr Shaaban Hanafy ${ }^{1 *}$ [D and Essam Elsayed Tharwat ${ }^{2}$
}

\begin{abstract}
Background: PVT is an ultrasonographic finding in up to $8 \%$ of patients with liver cirrhosis. Once hepatocellular carcinoma has occurred as the final station in liver cirrhosis, the risk of PVT rises to $40 \%$. Benign and malignant PVT can occur in patients with liver cirrhosis, and it is important to differentiate the nature of PVT as it has a great impact on patient's management and outcome.

Diagnosis: Confirming portal vein thrombosis and extension by abdominal ultrasound, contrast-enhanced USG, CT, or MRI. Malignant criteria of PVT are pulsatile pattern in Doppler and heterogeneous contrast enhancement, which are especially seen at the arterial phase, neovascularity within PVT, portal vein thrombus with a diameter of $>23 \mathrm{~mm}$ while in benign thrombus, PV diameter does not exceed $20 \mathrm{~mm}$. Visible hypervascular tumor is in close proximity to PVT.
\end{abstract}

Conclusion: It is not uncommon to find portal vein thrombosis in patients with liver cirrhosis, despite the fact that malignant variant is the most frequent, but efforts should be gathered to exclude benign PVT which may change the management of the patients dramatically.

Keywords: Portal vein thrombosis, Cirrhosis, Benign, Malignant

\section{Introduction}

PVT is an ultrasonographic finding in up to $8 \%$ of patients with liver cirrhosis [1], and once hepatocellular carcinoma has occurred as the final station in liver cirrhosis, the risk of PVT rises to $40 \%$ [2].

Malignant PVT is an important determinant of tumor staging, as well as prognosis, and influences treatment selection; it indicates poor prognosis and is an absolute contraindication of liver transplantation (LT) due to unavoidable tumor recurrence also a contraindication for locoregional therapy, the dilemma is that benign PVT can occur also in liver cirrhosis and the hesitation to treat may negatively affect the patient's prognosis.

\footnotetext{
*Correspondence: Dr_amr_hanafy@yahoo.com

${ }^{1}$ Internal Medicine Department, Hepatogastroenterology Section,

Zagazig University, Zagazig, Egypt

Full list of author information is available at the end of the article
}

Portal venous system drains blood from the gastrointestinal tract (apart from the lower section of rectum), spleen, pancreas, and gallbladder to the liver. It is formed by the union of the splenic and superior mesenteric veins forming the confluence of portal vein, and drains directly into the liver, supplying nearly $75 \%$ of its hepatic blood flow [3]. Other tributaries of the PV include the left and right gastric veins, cystic veins, and the superior and inferior veins of Sappey. The inferior mesenteric vein (IMV) has greater variability, joining the splenic vein $(40 \%)$, the SMV (40\%), or the portal confluence (20\%) [4].

The main portal vein divides into two branches-the left (supplying segments I, II, III, and IV) and right portal veins which divides into two branches-the anterior (supplying segments V and VIII) and the posterior (supplying segments VI and VII) portal veins [4].

Normal portal vein peak systolic velocity is $20-40$ $\mathrm{cm} / \mathrm{s}$, a low flow velocity of $<16 \mathrm{~cm} / \mathrm{s}$ is one of diagnostic 
features of portal hypertension [5], cessation of portal flow is seen within areas of occlusion secondary to a benign or tumor thrombus, in the case of malignant PVT, the flow is pulsatile, while the flow is waveform in recanalized benign thrombus [6].

Pseudo thrombosis of the portal vein (Fig. 1) may be seen due to absence or opacification secondary to the Doppler settings or artifact formation, low velocities, depth of the vessel, Doppler angle of insonation/probe position, or masking by an overlying tissue [7].

\section{Pathogenesis}

The main mechanisms of PVT are due to disturbance of any element of the Virchow triad: sluggish portal blood flow which occurs commonly in liver cirrhosis, hepatobiliary malignancies mainly hepatocellular carcinoma, gastric carcinoma, or extrinsic compression by lymph node or tumor [8], vascular endothelial damage due to local inflammation or infection caused by acute pancreatitis, ascending cholangitis , omphalitis, appendicitis, cytomegalovirus hepatitis, tubercular lymphadenitis, diverticulitis, portal pyemia after infected internal piles, or invasion by malignant cells of HCC, abdominal, or surgical trauma (liver surgery, colon-rectal surgery, splenectomy, sleeve gastrectomy, cholecystectomy, pancreatectomy) [9].

Accentuated blood coagulation due to tissue factorFVIIa complex formation activates the conversion of prothrombin to thrombin which enhances coagulation [10], and antithrombin (AT) can control the activity of FVIIa by forming FVIIa-AT complex [11].

Causes of hypercoagulable states are inherited prothrombotic conditions as protein $C$ deficiency (5-10\%), $\mathrm{S}$ deficiency (5-30\%), factor $\mathrm{V}$ Leiden mutation (1-9\%), antithrombin deficiency (1-5\%), prothrombin G20210A mutation (5-40\%), and methylene tetrahydrofolate reductase gene mutation at position C677T s (10-50\%) [12].

Acquired thrombotic states as malignancy, myeloproliferative disorders , antiphospholipid syndrome, paroxysmal nocturnal hemoglobinuria, hyperhomocysteinemia, pregnancy, perperium, oral contraceptive pills, and other causes which include Behcet's disease, Celiac disease, and human immunodeficiency virus infection.

PVT is classified into thrombosis confined till beyond the union of the splenic and superior mesenteric veins; to the superior mesenteric vein, but with patent mesenteric vessels; to the whole splanchnic venous system, but with large collaterals; or extensive splanchnic venous thrombosis with few small collaterals [13].

Acute PVT favors benign behavior of the occlusion rather than malignancy and may present with significant right upper quadrant abdominal pain, ascites, and bowel infarction in vulnerable diabetic patients [14].

Chronic portal vein thrombosis with portal cavernoma, and portal cholangiopathy defined as deformation and obstruction of intrahepatic and extrahepatic bile ducts by the collateral veins of the portal cavernoma favors malignancy [15].

\section{Diagnosis}

In liver cirrhosis, the benign or malignant nature of PVT may not be easily distinguishable and remains a diagnostic challenge; benign and tumor thrombi can occur simultaneously [16], and the latter is a contraindication to liver transplantation. Sometimes, Porta hepatis masses as lymph nodes or cholangiocarcinoma may compress the portal vein and may be mistaken for PVT or may be present at the same time with PVT.

Exclusion of hypercoagulable states by testing for JAK2 V617F mutation, exon 9 mutations by either deletion or insertion in the calreticulin gene have recently observed

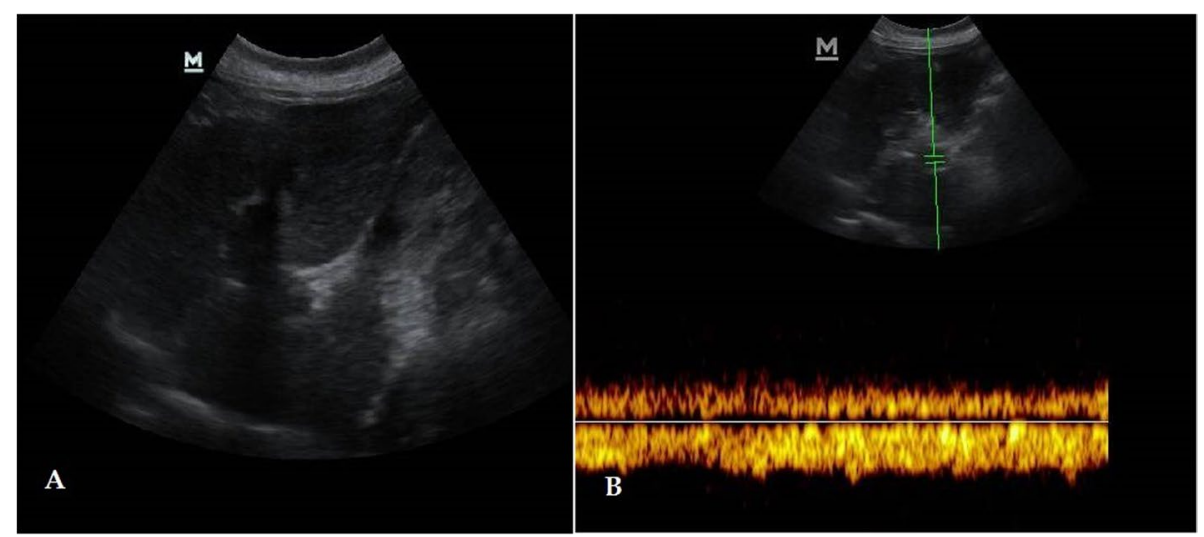

Fig. 1 A Portal vein pseudothrombosis. B Pseudothrombosis with reversed portal flow 
but has a lower risk of PVT [17], bone marrow biopsy, and erythropoietin levels for myeloproliferative disorders, anticardiolipin antibodies, lupus anticoagulant, or anti-b2 glycoprotein 1 antibodies for antiphospholipid syndrome. Flow cytometry is used to detect presence of CD55- and CD59-deficient clone for paroxysmal nocturnal hemoglobinuria and to determine plasma levels of antithrombin, protein $\mathrm{C}$, and protein $\mathrm{S}$, protein $\mathrm{C}$-activated resistance or molecular analysis of R605Q mutation, molecular analysis of the G20210A mutation, serum homocysteine levels, and molecular analysis of C677T polymorphism [9-12].

\section{Radiographic findings}

In case of benign PVT, there is a thrombus with features of ischemic bowel if superior mesenteric venous (SMV) was significantly involved. In malignant PVT with slowly progressive growth, cavernous transformation of the portal vein may be seen, with numerous periportal collaterals $[18,19]$.

\section{Abdominal ultrasound (Fig. 2)}

It may be not easy to see the hypoechoic thrombus with grey-scale imaging. Color Doppler shows absent flow in the portal vein and even to detect partial thrombosis. The SMV, intrahepatic branches of the portal vein, and hepatic veins should also be examined to assess the extent of thrombosis; malignant thrombus will show internal color vascularity, and benign thrombus is avascular on color Doppler [20].

False-negative results occur only in partial PVT and isolated superior mesenteric vein thrombosis [21]. Drawbacks of USG are difficult in obese patients, significant bowel distension, and lack of diagnosis of associated bowel ischemia. CT and MRI are preferred due to the ability of detecting bowel ischemia, septic foci, abdominal malignancies, and thrombosis in the splenic and superior mesenteric veins [22].

\section{Contrast-enhanced ultrasound (CEUS)}

The contrast agent was a suspension of stabilized sulphur hexafluoride microbubbles in saline (SonoVue, Bracco $\mathrm{SpA})$. SonoVue was reconstituted just before administration by adding $5 \mathrm{ml}$ of sterile saline to the vial. After injection of a single intravenous bolus of $5 \mathrm{ml}$ of contrast medium, a US scan along the main axis of the PVT was obtained and kept for $1.5 \mathrm{~min}$. Presence of pulsatile arterial signals and early arterial enhancement (within $25 \mathrm{~s}$ ) of the thrombus on CEUS were considered diagnostic for malignant PVT [20].

\section{Computed tomography (CT) (Fig. 3)}

Non-contrast CT scans may be unable to identify PVT. The diagnosis can be made on portal venous phase as complete or partial non-opacification of part or the whole portal vein. Transient hepatic attenuation differences (THAD) in the arterial/early portal phase, showing increased enhancement due to augmented perfusion of the lobe or segment previously supplied by the occluded branch due to hepatic arterial compensatory flow [23], thrombus enhancement is highly suggestive of malignant thrombus [24].

\section{Magnetic resonance imaging (MRI) (Fig. 4)}

The ability of diffusion-weighted (DW) imaging to differentiate benign from malignant liver lesions was investigated; the increased cellular density and altered nucleo-cytoplasmic ratio showed a restricted water molecule diffusion and reduced apparent diffusion coefficients
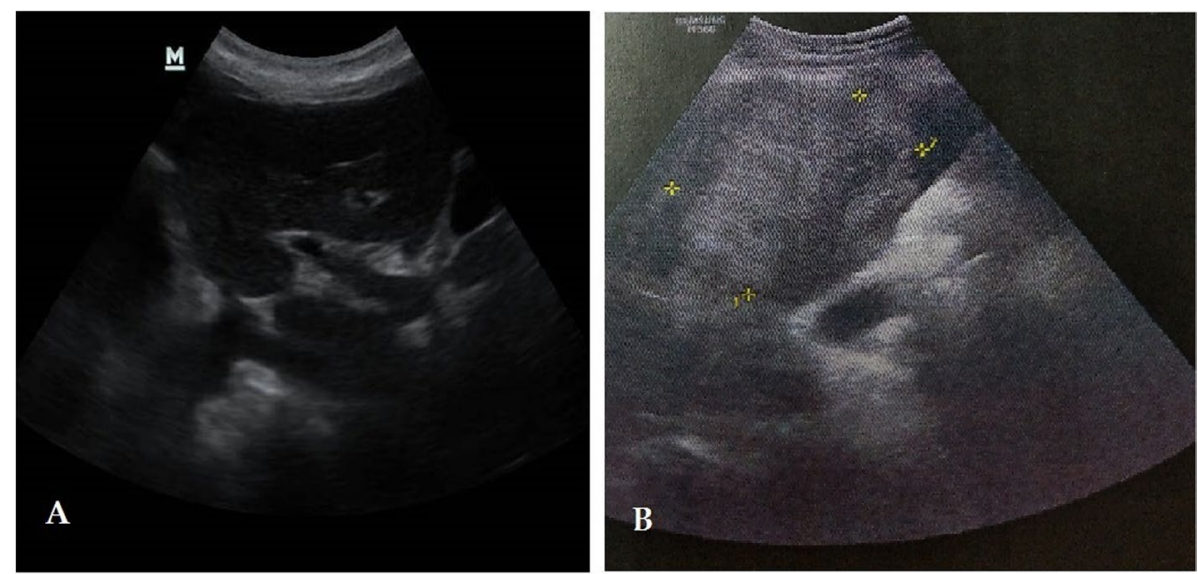

Fig. 2 A Non-malignant portal vein thrombosis. B HCC with malignant PVT 

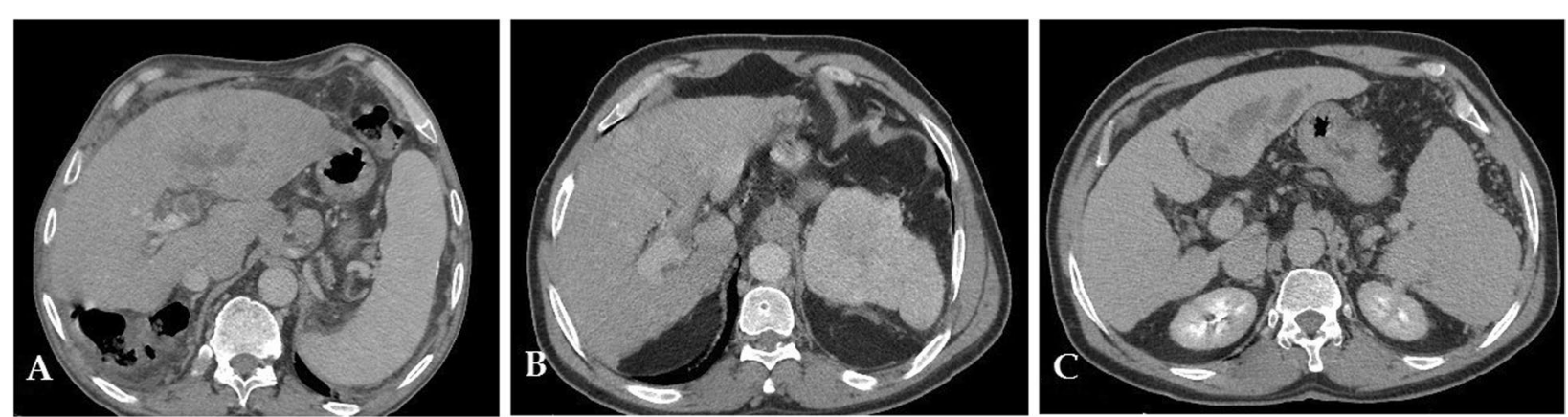

Fig. 3 A Triphasic CT infiltrative HCC with malignant LT PV thrombus. B Triphasic CT LT PV malignant thrombus at portal phase. C Triphasic CT malignant LT PV thrombus washout at delayed phase
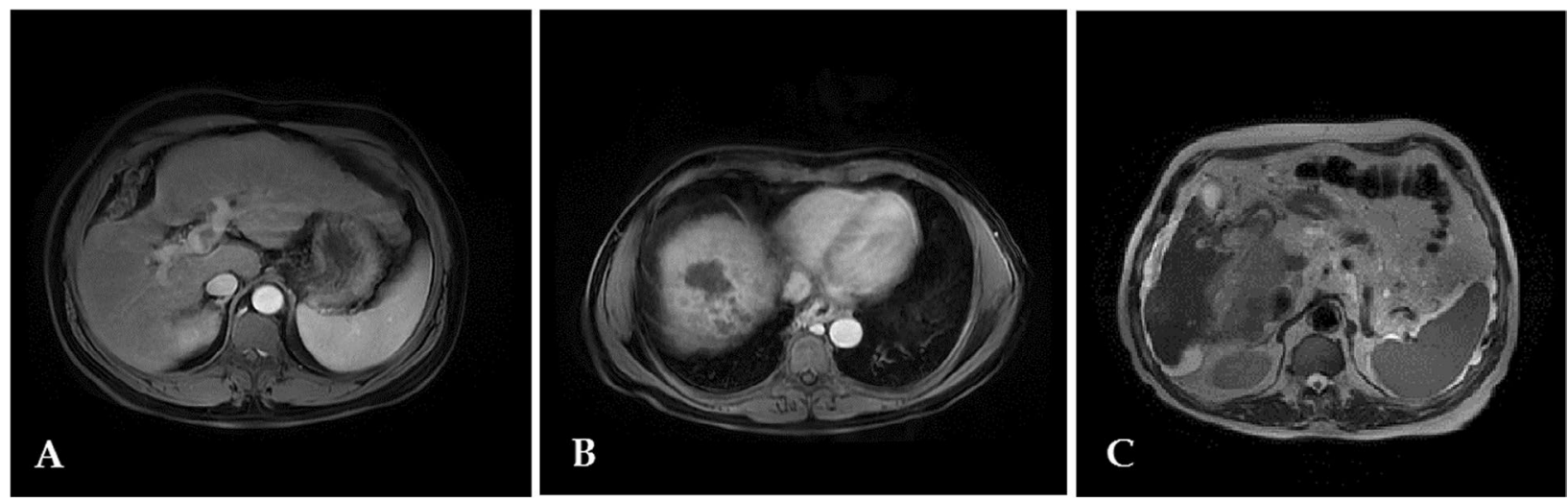

Fig. 4 A MRI arterial phase bland thrombus with no enhancement. B MRI DWI restricted PV thrombus and HCC at RT Iobe. C MRI T2WI HCC and malignant PV thrombus lost vascular signal void

when compared with benign lesions; however, some overlap may occur [25].

3D contrast-enhanced MRA is the most sensitive sequence. according to the physics of MRI; it is divided according to TE (time to echo), TR (time of repetition) into T1-weighted [short TR $(500 \mathrm{~ms})$, TE $(14 \mathrm{~ms})$ ], T2-weighted [longer TR (4000 ms), TE (90 ms)], or Flair [very long TR (9000), TE (114)] [25], malignant thrombus is hyper intense, $\mathrm{T} 1$ + gadolinium the tumor thrombus enhancement may be detectable on post-contrast dynamic sequences [26].

Contrast-enhanced MRI (Gadolinium) may precipitate nephrogenic systemic fibrosis in case of acute renal failure [27], in addition to the high cost and artifacts due to patient irritability.

\section{F-fluorodeoxyglucose poistron emission tomography/ computed tomography (PET CT)}

Metabolic activity was measured using the maximum standardized uptake value (SUV max) at the site of thrombus, and it may have a promising ability to differentiate between benign and malignant thrombus; in benign thrombus, no or slight FDG-avidity while malignant thrombus has a moderate to high avidity to FDG, a research documented that SUV max of malignant thrombus $(6.37 \pm 2.67)$ was significantly higher than that of benign thrombus $(2.87 \pm 1.47 ; P<0.01)$ [28] with other possible benefits of PET/CT as visualization of further sites of thrombosis.

So finally, malignant criteria of PVT are pulsatile pattern in Doppler, heterogeneous contrast enhancement, especially seen at the arterial phase, neovascularity within PVT, portal vein thrombus with a diameter of $>$ $23 \mathrm{~mm}$ while in benign thrombus PV diameter does not exceed $20 \mathrm{~mm}$ [29], visible hypervascular tumor in close proximity to PVT, or present as an arterioportal fistula if paraumbilical vein is recanalized [30].

\section{Liver biopsy}

The golden reference is biopsy from thrombi that are located in the intrahepatic portal vein by 22 Gauge Chiba Needle, and with the help of color Doppler USG, FNAC was retrieved from thrombus that was nearest to the hepatic mass and most suspicious ones on color Doppler 
US, biopsy path should avoid hepatic artery and major vessels, and segments of liver involved by tumor should be avoided to prevent false-positive result, the tissue obtained by gentle back and forth movement into the thrombus and without aspiration to avoid blood contamination [20].

\section{Endoscopic ultrasound (EUS)}

Endosonography may be useful in differentiating a benign from malignant thrombus by providing cytopathology by FNA. Transabdominal approach carries the risk of serious biliary or vascular injury. EUS-guided FNA may be of benefit in extrahepatic PVT via transduodenal approach [31].

\section{Therapy}

The approach to the management of PVT is critical and needs more efforts (Fig. 5); confirming portal vein thrombosis, behavior either benign or malignant and extension by contrast-enhanced USG, CT, or MRI according to the availability [32].

\section{Benign thrombosis}

Early anticoagulation of benign thrombus may significantly improve recanalization if started within the first week after the diagnosis, and the duration of anticoagulation may extend for at least 6 months [33].

Close monitoring for possible mesenteric infarction and the risk is high with involvement of mesenteric vessels and poor collateral circulation. The treatment is by intestinal resection, and radiological signs of intestinal ischemia are the halo sign of intestinal wall edema, pneumatosis intestinalis, and pneumoperitoneum [34].

Thrombolysis should be done with high caution due to high mortality and complications, long-term anticoagulation is indicated in patients with underlying prothrombotic disorder, recurrent thrombotic episodes, previous intestinal ischemia, or a family history of deep venous thrombosis, specific management of underlying hematological diseases.

Before management some points should be considered:

\section{Liver cirrhosis}

Ultrasonographic features include surface nodularity, coarse hepatic echotexture, prominent caudate lobe, caudate/right lobe ratio $>0.66$, splenomegaly, splenic vein diameter, renal artery resistive index $>0.8$, thrombocytopenia $<100.000$, fibroscan $>12$ kps especially in case of indeterminate imaging features, care should be provided regarding anticoagulation, Child-Pugh class, and possibility of esophageal varices (EV) should be excluded.

\section{The acuity of thrombosis}

Features suggestive of an acute thrombosis include the presence of low intensity thrombus in radiology, and portal vein may appear dilated. The absence of portosystemic collaterals or splenomegaly may indicate an acute thrombosis; however, chronic PVT is suspected in the presence of a cavernous transformation which may need only up to 20 days after acute PVT [35], and calcifications are signs of chronic PVT which is better visualized by USG or CT [36].

\section{Clinical sequelae of PVT}

PVT causes pre-hepatic rise of portal pressure in both cirrhotic and non-cirrhotic profiles with development of EVs in more than $70 \%$ of patients, so it was recommended to endoscopically screen for EV within the first 2-3 months following the onset of acute PVT in non-cirrhotic patients and if negative it should be rescreened after 6-12 months and at 2- to 3-year intervals thereafter as varices develop in $22 \%$ after 3 years [37].

In the context of PVT, upper GIT bleeding should derive for advanced radiological investigations to detect porto-systemic collaterals mainly the ectopic one and assess for TIPS or embolization of collaterals or shunt surgery whenever appropriate.

\section{Portal cholangiopathy}

This form of cholangiopathy is caused by ischemic pressure by the peribiliary portal collaterals and reduced portal blood flow due to PVT manifested as right abdominal pain, pruritus, jaundice, gallbladder stones, and cholangitis [38], It is now preferred to be diagnosed with magnetic resonance cholangiopancreatography which is also the investigation of choice in making differential diagnosis with hilar cholangiocarcinoma [15].

\section{Thrombolysis}

It is indicated in patients with cirrhosis if superior mesenteric vein is involved or if the patient carries a known prothrombotic condition [39]. In non-cirrhotic acute extrahepatic portal vein obstruction, anticoagulant therapy with low molecular weight heparin followed by oral anticoagulation is recommended for at least 6 months, and long-term anticoagulation should be considered if a persistent prothrombotic state is present.

Unfractionated heparin has been largely replaced by LMWH in most clinical situations due to the ease of administration, given subcutaneously without the need for laboratory follow up. The recommended dose for enoxaparin is $1 \mathrm{mg} / \mathrm{kg}$ every $12 \mathrm{~h}$ (maximum dose $150 \mathrm{mg}$ ) enoxaparin at a dose of $1 \mathrm{mg} / \mathrm{kg}$ twice a day 


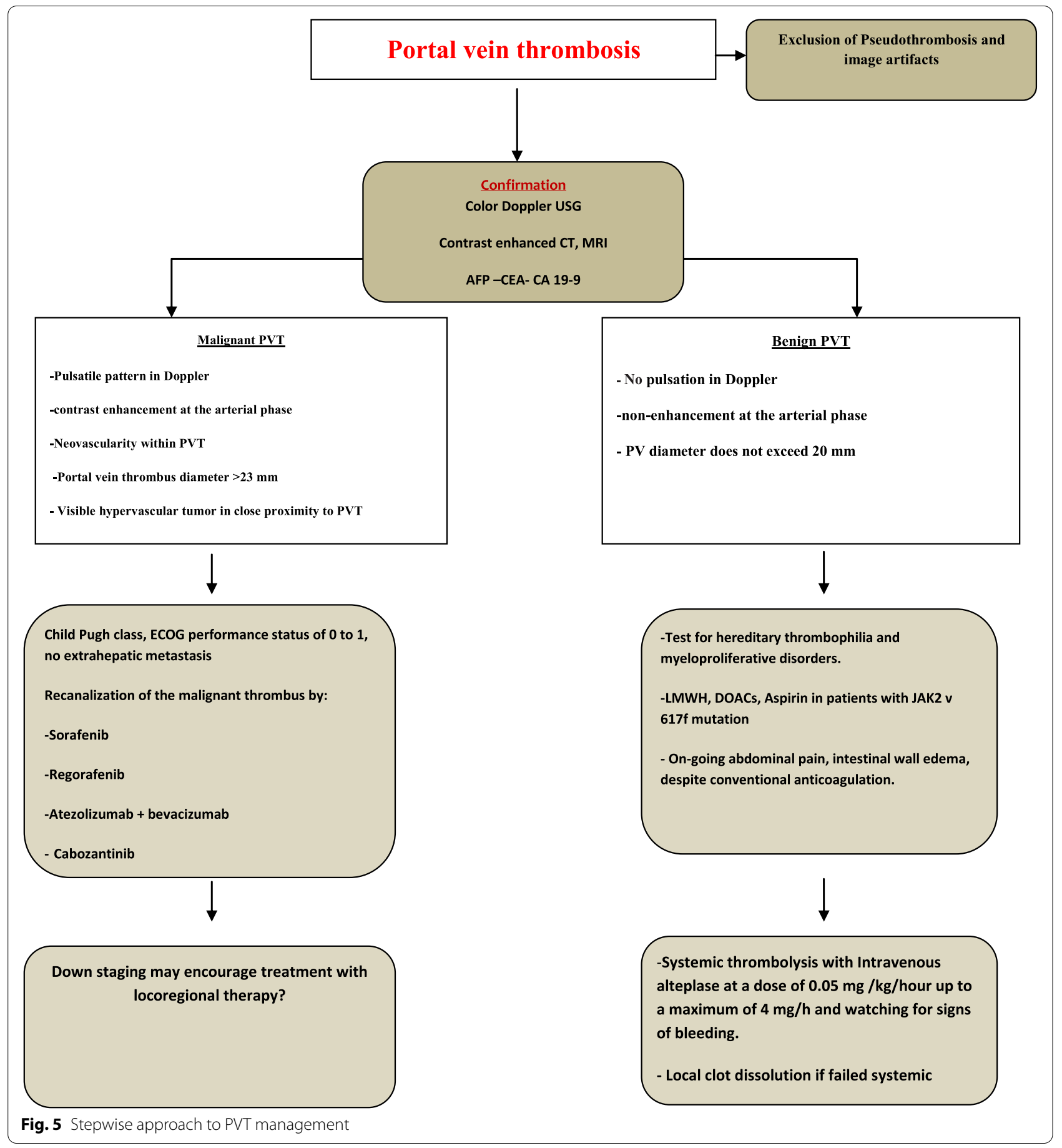

was associated with 4-folds lower risk of non-variceal bleeding than a $1.5-\mathrm{mg} / \mathrm{kg}$ once a day dose.

Anti-Xa level follow-up may be indicated in morbid obesity, renal impairment (creatinine clearance $<30 \mathrm{ml} /$ min), pregnancy, significant burns, and recurrent thrombosis while the patient is on LMWH treatment.
Direct-acting oral anticoagulants (DOACs) include orally available direct factor Xa inhibitors (rivoraxaban, apixaban, edoxaban, betrixaban) and the direct thrombin inhibitor dabigatran were used. It should be avoided at creatinine clearance $<15 \mathrm{ml} / \mathrm{min}$ and advanced liver cirrhosis [Child-Pugh class $\mathrm{C}$ ]. 


\section{Systemic thrombolysis}

It is indicated in acute PVT with persistent abdominal pain with signs of intestinal ischemia in the absence of free fluid which denote perforation and after exclusion of absolute contraindications as major surgery in the previous 2 weeks, previous cerebral hemorrhage in the preceding 12 months, allergy, fibrinogen below $100 \mathrm{mg} /$ $\mathrm{dl}$, or thrombocytopenia $<50,000 \times 10^{9} / \mathrm{L}$.

Patients who fulfilled the inclusion criteria would be given intravenous Alteplase at a dose of $0.05 \mathrm{mg} / \mathrm{kg} / \mathrm{h}$, up to a maximum of $4 \mathrm{mg} / \mathrm{h}$ for up to $72 \mathrm{~h}$. Patients should be monitored for bleeding from body orifices, sites of venipuncture, daily laboratory testing for complete blood count, fibrinogen level, prothrombin time, international normalized ratio, liver, and kidney function tests [40].

\section{Local clot dissolution}

If intestinal ischemia persists with ongoing abdominal pain despite systemic thrombolysis, local clot dissolution should be discussed after taking the patient's consent. Systemic thrombolysis and anticoagulation were interrupted for 8-12 h. A transjugular approach to create an intrahepatic portosystemic shunt through which local thrombolysis [41] will be given through infusion of tPA at a dose of $1 \mathrm{mg} / \mathrm{h}$ until satisfactory improvement. Mechanical thrombectomy through interventional radiology and transjugular central access was maintained for $24 \mathrm{~h}$ to do a follow-up portal angiography with a possibility of re-intervention. Success in treatment of acute PVT should be followed by long term coagulation with rivaroxaban or other DOACs and regular radiological follow up.

\section{Malignant portal vein thrombosis}

Thrombolysis and anticoagulation do not apply for malignant PVT, as the portal vein is occluded by viable tumorous tissue, instead, Patients with Child-Pugh class A with Eastern Cooperative Oncology Group (ECOG) performance status of 0 to 1 , and in absence of extrahepatic metastasis can be offered systemic therapy aiming to step-down the patient stage to become fit for locoregional therapy.

Systemic therapy includes multikinase inhibitors as sorafenib which was approved as the first line agent for advanced $\mathrm{HCC}$, and it has been associated with improved overall survival (OS) as compared with placebo [3]. The main side effects are diarrhea, fatigue, and palmar-plantar erythrodysesthesia.

Lenvatinib is noninferior to sorafenib (13.6 vs 12.3 months; HR, 0.92; 95\% CI, 0.79-1.06) with the same side effects as hypertension, diarrhea, fatigue, weight loss, and palmar-plantar erythrodysesthesia [42].

Atezolizumab which selectively targets PD-L1 preventing interactions with $\mathrm{PD}-1$ and $\mathrm{B} 7-1$ receptors, so antagonizing $\mathrm{T}$ cell suppression, With Bevacizumab which is a monoclonal antibody that targets vascular endothelial growth factor, inhibiting angiogenesis and tumor growth [43], for the treatment of adult patients with unresectable locally advanced or metastatic hepatocellular carcinoma (HCC) with no prior systemic treatment had been recently approved by FDA. The promising results of The IMbrave 150 study which is a global, multi-center, randomized phase III trial evaluating the efficacy and safety of atezo-bev when compared with sorafenib in unresectable HCC patients who received no prior systemic therapy. It showed a significant improvement in overall survival HR 0.58; 95\% CI, $0.42-0.79$ and progression free survival (HR, 0.59; $95 \%$ CI, 0.47-0.76) in patients treated with this combination [44].

Patients who do not respond adequately may get benefit from Regorafenib as a second line therapy for patients with advanced HCC who progressed with sorafenib and showed tolerance to sorafenib at a dose of at least $400 \mathrm{mg}$ daily without progression above Child-Pugh A cirrhosis and an ECOG status [45].

Cabozantinib, a tyrosine kinase inhibitor, was shown to improve OS in patients who did not respond positively to first and/or second line therapies also in patients with Child-Pugh A with an ECOG of 0 to 1 [46] who progressed or were intolerant to sorafenib with an alpha fetoprotein $>400 \mathrm{ng} / \mathrm{ml}$ [47].

Nivolumab, a programmed death receptor-1 (PD-1) inhibitor, was studied in sorafenib-naive and experienced patients with Child-Pugh A and an ECOG status of 0 to 1. Overall tumor response rate was $16 \%$, and it may have the potential to induce immune-mediated AEs, including autoimmune hepatitis, colitis, pneumonitis, and uveitis, however, in less than 5\% [48].

Finally, it is not uncommon to find portal vein thrombosis in patients with advanced liver cirrhosis, despite the fact that malignant variant is the most frequent as the hepatic microenvironment become more prone to carcinogenesis $[49,50]$, but efforts should be gathered to exclude benign PVT which may change the management of the patients dramatically.

\section{Authors' contributions}

Amr Hanafy contributed to the collection of data and drafted the manuscript. Essam Elsayed Tharwat provided the radiological images of some patients. All authors approved the final manuscript, including the authorship list.

Funding

No funding agent. 


\section{Availability of data and materials \\ N/A.}

\section{Declarations}

\section{Ethics approval and consent to participate}

The study was carried out following the Helsinki Declaration.

\section{Consent for publication}

Not applicable as it is a review article.

\section{Competing interests}

No competing interests.

\section{Author details}

IInternal Medicine Department, Hepatogastroenterology Section, Zagazig University, Zagazig, Egypt. ${ }^{2}$ Diagnostic Radiology, Zagazig University, Zagazig, Egypt.

Received: 10 Auqust 2021 Accepted: 23 November 2021 Published online: 14 December 2021

\section{References}

1. Amitrano L, Brancaccio V, Guardascione MA, Margaglione M, lannaccone L, D'Andrea G, Marmo R, Ames PR, Balzano A (2000) Inherited coagulation disorders in cirrhotic patients with portal vein thrombosis. Hepatol 31:345-348 [PMID: 10655256. https://doi.org/10.1002/hep.510310213

2. Zocco MA, Di Stasio E, De Cristofaro R, Novi M, Ainora ME, Ponziani F, Riccardi L, Lancellotti S, Santoliquido A, Flore R, Pompili M, Rapaccini GL, Tondi P, Gasbarrini GB, Landolfi R, Gasbarrini A (2009) Thrombotic risk factors in patients with liver cirrhosis: correlation with MELD scoring system and portal vein thrombosis development. J Hepatol 51(4):682-689. [PMID: 19464747. https://doi.org/10.1016/j.jhep.2009.03.013

3. Corness JA, McHugh K, Roebuck DJ, Taylor AM (2006) The portal vein in children: radiological review of congenital anomalies and acquired abnormalities. Pediatr Radiol 36:87-96. [PMID: 16284764. https://doi.org/ 10.1007/s00247-005-0010-4

4. Lee WK, Chang SD, Duddalwar VA, Comin JM, Perera W, Lau WF, Bekhit EK, Hennessy OF (2011) Imaging assessment of congenital and acquired abnormalities of the portal venous system. Radiographics 31:905-926. [PMID: 21768231. https://doi.org/10.1148/rg.314105104

5. Al-Nakshabandi NA (2006) The role of ultrasonography in portal hypertension. Saudi J Gastroenterol 12:111-117. [PMID: 19858596. https://doi org/10.4103/1319-3767.29750

6. Iranpour P, Lall C, Houshyar R, Helmy M, Yang A, Choi J, Ward G, Goodwin SC (2016) Altered Doppler flow patterns in cirrhosis patients: an overview. Ultrasonography 35(1):3-12. [PMID: 26169079. https://doi.org/10.14366/ usg. 15020

7. Kruskal JB, Newman PA, Sammons LG, Kane RA (2004) Optimizing Doppler and color flow US: application to hepatic sonography. Radiographics 24:657-675. [PMID: 15143220. https://doi.org/10.1148/rg.243035139

8. DeLeve LD, Valla D-C, Garcia-Tsao G (2009) Vascular disorders of the liver. Hepatology 49:1729-1764. [PMID: 19399912. https://doi.org/10.1002/ hep. 22772

9. Primignani M, Mannucci P (2008) The role of thrombophilia in splanchnic vein thrombosis. Semin Liver Dis 28:293-301. [PMID: 18814082. https:// doi.org/10.1055/s-0028-1085097

10. Mackman N (2009) The role of tissue factor and factor Vlla in hemostasis. Anesth Analg 108(5):1447-1452. [PMID: 19372318. https://doi.org/10. 1213/ane.0b013e31819bceb1

11. Bajaj MS, Birktoft JJ, Steer SA, Bajaj SP (2001) Structure and biology of tissue factor pathway inhibitor. Thromb Haemost 86:959-972 PMID: 11686353

12. Plessier A, Rautou P-E, Valla D-C (2012) Management of hepatic vascular diseases. J Hepatol 56:S25-S38. [PMID: 22300463. https://doi.org/10. 1016/S0168-8278(12)60004-X
13. Jamieson NV (2000) Changing perspectives in portal vein thrombosis and liver transplantation. Transplantation 69(9):1772-1774. [PMID: 10830208. https://doi.org/10.1097/00007890-200005150-00006

14. Elkrief L, Corcos O, Bruno O, Larroque B, Rautou PE, Zekrini K, Bretagnol F, Joly F, Francoz C, Bondjemah V, Cazals-Hatem D, Boudaoud L, De Raucourt E, Panis Y, Goria O, Hillaire S, Valla D, Plessier A (2014) Type 2 diabetes mellitus as a risk factor for intestinal resection in patients with superior mesenteric vein thrombosis. Liver Int 34(9):1314-1321. [PMID: 24237969. https://doi.org/10.1111/liv.12386

15. Llop E, de Juan C, Seijo S, García-Criado A, Abraldes JG, Bosch J, GarcíaPagán JC (2011) Portal cholangiopathy: radiological classification and natural history. Gut 60(6):853-860. [PMID: 21270119. https://doi.org/10. 1136/gut.2010.230201

16. Sotiropoulos GC, Radtke A, Schmitz KJ, Molmenti EP, Schroeder T, Saner FH, Baba HA, Fouzas I, Broelsch CE, Malagó M, Lang H (2008) Liver transplantation in the setting of hepatocellular carcinoma and portal vein thrombosis: a challenging dilemma? Dig Dis Sci 53(7):1994-1999. [PMID: 18080191. https://doi.org/10.1007/s10620-007-0099-4

17. Kim BH, Cho YU, Bae MH, Jang S, Seo EJ, Chi HS, Choi Y, Kim DY, Lee JH, Lee JH, Lee KH, Park YM, Lee JK, Park CJ (2015) JAK2 V617F, MPL, and CALR Mutations in Korean patients with essential thrombocythemia and primary myelofibrosis. J Korean Med Sci 30(7):882-888. [PMID: 26130950. https://doi.org/10.3346/jkms.2015.30.7.882

18. Bittencourt PL, Couto CA, Ribeiro DD (2011) Portal vein thrombosis and BuddChiari syndrome. Hematol Oncol Clin North Am 25:1049-1066. [PMID: 19150317. https://doi.org/10.1016/j.cld.2008.10.002

19. Walser EM, Runyan BR, Heckman MG, Bridges MD, Willingham DL, PazFumagalli R, Nguyen JH (2011) Extrahepatic portal biliopathy: proposed etiology on the basis of anatomic and clinical features. Radiology 258(1):146-153. [PMID: 21045178. https://doi.org/10.1148/radiol.10090 923

20. Tarantino L, Francica G, Sordelli I, Esposito F, Giorgio A, Sorrentino P, de Stefano G, Di Sarno A, Ferraioli G, Sperlongano P (2006) Diagnosis of benign and malignant portal vein thrombosis in cirrhotic patients with hepatocellular carcinoma: color Doppler US, contrast-enhanced US, and fine-needle biopsy. Abdom Imaging 31:537-544 [PMID: 16865315. https://doi.org/10.1007/s00261-005-0150-x

21. Bach AM, Hann LE, Brown KT, Getrajdman GI, Herman SK, Fong Y, Blumgart LH (1996) Portal vein evaluation with US: comparison to angiography combined with CT arterial portography. Radiology 201:149-154. [PMID: 8816536. https://doi.org/10.1148/radiology.201.1.8816536

22. Cristina Margini C, Berzigotti A (2017) Portal vein thrombosis: The role of imaging in the clinical setting. Dig Liver Dis 49(2):113-120. [PMID: 27965037. https://doi.org/10.1016/j.dld.2016.11.013

23. Wong H, Desser TS, Jeffrey RB (2015) Transient hepatic attenuation differences in computed tomography from extrahepatic portal vein compression. Radiol Case Rep 3(1):113.[PMID: 27303501. https://doi.org/10.2484/ rcr.v3i1.113

24. Bruegel M, Holzapfel K, Gaa J, Woertler K, Waldt S, Kiefer B, Stemmer A, Ganter C, Rummeny EJ (2008) Characterization of focal liver lesions by ADC measurements using a respiratory triggered diffusion-weighted single-shot echo-planar MR imaging technique. Eur Radiol 18(3):477-485. [PMID: 17960390. https://doi.org/10.1007/s00330-007-0785-9

25. Currie S, Hoggard N, Craven IJ, Hadjivassiliou M, Wilkinson ID ID (2013) Understanding MRI: basic MR physics for physicians. Postgrad Med J 89:209-223. [PMID: 23223777. https://doi.org/10.1136/postgradme dj-2012-131342

26. Lin J, Zhou KR, Chen ZW, Wang JH, Wu ZQ, Fan J (2003) Three-dimensional contrast-enhanced MR angiography in diagnosis of portal vein involvement by hepatic tumors. World J Gastroenterol 9(5):1114-1118. [PMID: 12717869. https://doi.org/10.3748/wjg.v9.i5.1114

27. Tweedle MF (2018) Science to practice: will gadolinium chelates be replaced by iron chelates in MR imaging? Radiology 286(2):409-411. [PMID: 29356647. https://doi.org/10.1148/radiol.2017172305

28. Hu S, Zhang J, Cheng C, Liu Q, Sun G, Zuo C (2014) The role of 18F-FDG $\mathrm{PET} / \mathrm{CT}$ in differentiating malignant from benign portal vein thrombosis. Abdom Imaging 39(6):1221-1227. [PMID: 24913670. https://doi.org/10. 1007/s00261-014-0170-5

29. Berzigotti A, García-Criado A, Darnell A, García-Pagán JC (2014) Imaging in clinical decision-making for portal vein thrombosis. Nat Rev 
Gastroenterol Hepatol 11(5):308-316. [PMID: 24419395. https://doi.org/ 10.1038/nrgastro.2013.258

30. Carneiro C, Brito J, Bilreiro C, Barros M, Bahia C, Santiago I, Caseiro-Alves F (2019) All about portal vein: a pictorial display to anatomy, variants and physiopathology. Insights Imaging 10(1):38. [PMCID: PMC6428891. https://doi.org/10.1186/s13244-019-0716-8

31. Michael H, Lenza C, Gupta M, Katz DS (2011) Endoscopic ultrasound -guided fine-needle aspiration of a portal vein thrombus to aid in the diagnosis and staging of hepatocellular carcinoma. Gastroenterol Hepatol (NY) 7:124-129 PMID: 21475421

32. Condat B, Pessione F, Helene Denninger M, Hillaire S, Valla D (2000) Recent portal or mesenteric venous thrombosis: increased recognition and frequent recanalization on anticoagulant therapy. Hepatology 32:466-470. [PMID: 10960436. https://doi.org/10.1053/jhep.2000.16597

33. Turnes J, Pagan JCG, Gonzalez M, Aracil C, Calleja JL, Ripoll C, Abraldes JG, Bañares R, Villanueva C, Albillos A, Ayuso JR, Gilabert R, Bosch J (2008) Portal hypertension-related complications after acute portal vein thrombosis: impact of early anticoagulation. Clin Gastroenterol Hepatol 6:1412-1417. [PMID: 19081529. https://doi.org/10.1016/j.cgh.2008.07.031

34. Kanasaki S, Furukawa A, Fumoto K, Hamanaka Y, Ota S, Hirose T Inoue A, Shirakawa T, Hung Nguyen LD, Tulyeubai S. Acute mesenteric ischemia: multidetector CT findings and endovascular management. Radiographics 2018;38:945-961. [PMID: 29757725 DOl: https://doi.org/10.1148/rg. 2018170163]

35. De Gaetano AM, Lafortune M, Patriquin H, De Franco A, Aubin B, Paradis K (1995) Cavernous transformation of the portal vein: patterns of intrahepatic and splanchnic collateral circulation detected with Doppler sonography. AJR Am J Roentgenol 165:1151-1155. [PMID: 7572494. https://doi. org/10.2214/ajr.165.5.7572494

36. Brancatelli G, Federle MP, Pealer K, Geller DA (2001) Portal venous thrombosis or sclerosis in liver transplantation candidates: preoperative CT findings and correlation with surgical procedure. Radiology 220:321-328. [PMID: 11477232. https://doi.org/10.1148/radiology.220.2.r01au23321

37. Noronha Ferreira C, Seijo S, Plessier A, Silva-Junior G, Turon F, Rautou PE, Baiges A, Bureau C, Bosch J, Hernández-Gea V, Valla D, García-Pagan JC (2016) Natural history and management of esophagogastric varices in chronic noncirrhotic, nontumoral portal vein thrombosis. Hepatology 63(5):1640-1650. [PMID: 26799606. https://doi.org/10.1002/hep.28466

38. Puri $P$ (2014) Pathogenesis of portal cavernoma cholangiopathy: is it compression by collaterals or ischemic injury to bile ducts during portal vein thrombosis? J Clin Exp Hepatol 4:S27-S33. [PMID: 25755592. https:// doi.org/10.1016/j.jceh.2013.05.015

39. de Franchis R, Baveno VI (2015) Faculty. Expanding consensus in portal hypertension: report of the Baveno VI consensus workshop: stratifying risk and individualizing care for portal hypertension. J Hepatol 63:743-752.[ PMID: 26047908. https://doi.org/10.1016/j.jhep.2015.05.022

40. Benmassaoud A, AlRubaiy L, Yu D, Chowdary P, Sekhar M, Parikh P, Finkel J, See TC, O'Beirne J, Leithead JA, Patch D (2019) A stepwise thrombolysis regimen in the management of acute portal vein thrombosis in patients with evidence of intestinal ischaemia. Aliment Pharmacol Ther 50(9):1049-1058. [PMID: 31489698. https://doi.org/10.1111/apt.15479

41. Tavare AN, Wigham A, Hadjivassilou A, Alvi A, Papadopoulou A, Goode A, Woodward N, Patch D, Yu D, Davies N (2017) Use of transabdominal ultrasound-guided transjugular portal vein puncture on radiation dose in transjugular intrahepatic portosystemic shunt formation. Diagn Interv Radiol 23(3):206-210. [PMID: 28223261. https://doi.org/10.5152/dir.2016. 15601

42. Kudo M, Finn RS, Qin S, Han KH, Ikeda K, Piscaglia F, Baron A, Park JW, Han G, Jassem J, Blanc JF, Vogel A, Komov D, Evans TRJ, Lopez C, Dutcus C, Guo M, Saito K, Kraljevic S, Tamai T, Ren M, Cheng AL (2018) Lenvatinib versus sorafenib in first-line treatment of patients with unresectable hepatocellular carcinoma: a randomized phase 3 non-inferiority trial. Lancet 391:1163-1173. [PMID: 29433850. https://doi.org/10.1016/S01406736(18)30207-1

43. Morse MA, Sun W, Kim R, He AR, Abada PB, Mynderse M, Finn RS (2019) The role of angiogenesis in hepatocellular carcinoma. Clin Cancer Res 25:912-920. [PMID: 30274981. https://doi.org/10.1158/1078-0432. CCR-18-1254

44. Finn RS, Qin S, Ikeda M, Galle PR, Ducreux M, Kim TY, Kudo M, Breder V, Merle P, Kaseb AO, Li D, Verret W, Xu DZ, Hernandez S, Liu J, Huang C, Mulla S, Wang Y, Lim HY, Zhu AX, Cheng AL (2020) IMbrave150
Investigators. Atezolizumab plus Bevacizumab in Unresectable Hepatocellular Carcinoma. N Engl J Med 382(20):1894-1905. [PMID: 32402160. https://doi.org/10.1056/NEJMoa1915745

45. Parikh ND, Singal AG, Hutton DW (2017) Cost effectiveness of Regorafenib as second-line therapy for patients with advanced hepatocellular carcinoma. Cancer 123:3725-3731.[PMID: 28662266. https://doi.org/10.1002/ cncr.30863

46. Abou-Alfa GK, MeyerT, Cheng AL, El-Khoueiry AB, Rimassa L, Ryoo BY, Cicin I, Merle P, Chen Y, Park JW, Blanc JF, Bolondi L, Klümpen HJ, Chan SL, Zagonel V, Pressiani T, Ryu MH, Venook AP, Hessel C, Borgman-Hagey AE, Schwab G, Kelley RK (2018) Cabozantinib in patients with advanced and progressing hepatocellular carcinoma. N Engl J Med 379(1):54-63. [PMID: 29972759. https://doi.org/10.1056/NEJMoa1717002

47. Zhu AX, Galle PR, Kudo M, Finn RS, Galle PR, Llovet JM, Abada P (2018) A study of ramucirumab (LY3009806) versus placebo in patients with hepatocellular carcinoma and elevated baseline alpha-fetoprotein (REACH-2). J Clin Oncol 36(Suppl. 4):TPS538. https://doi.org/10.1200/JCO.2018.36.4

48. El-Khoueiry AB, Sangro B, Yau T, Crocenzi TS, Kudo M, Hsu C, Kim TY, Choo SP, Trojan J, Welling THRD, Meyer T, Kang YK, Yeo W, Chopra A, Anderson J, Dela Cruz C, Lang L, Neely J, Tang H, Dastani HB, Melero I (2017) Nivolumab in patients with advanced hepatocellular carcinoma (CheckMate 040): an open-label, non-comparative, phase 1/2 dose escalation and expansion trial. Lancet 389(10088):2492-2502. [PMID: 28434648. https://doi.org/10.1016/S0140-6736(17)31046-2

49. Ogren M, Bergqvist D, Bjorck M, Acosta S, Eriksson H, Sternby NH (2006) Portal vein thrombosis: prevalence, patient characteristics and lifetime risk: a population study based on 23,796 consecutive autopsies. World J Gastroenterol 12:2115-2119. [PMID: 16610067. https://doi.org/10.3748/ wjg.v12.i13.2115

50. Costache RS, Dragomirică AS, Dumitraș EA, Mariana J, Căruntu A, Popescu A, Costache DO (2021) Portal vein thrombosis: A concise review (Review). Exp Ther Med 22(1):759. [PMID: 34035856. https://doi.org/10.3892/etm. 2021.10191

\section{Publisher's Note}

Springer Nature remains neutral with regard to jurisdictional claims in published maps and institutional affiliations.

\section{Submit your manuscript to a SpringerOpen ${ }^{\circ}$ journal and benefit from:}

- Convenient online submission

- Rigorous peer review

- Open access: articles freely available online

- High visibility within the field

- Retaining the copyright to your article

Submit your next manuscript at $\boldsymbol{\nabla}$ springeropen.com 